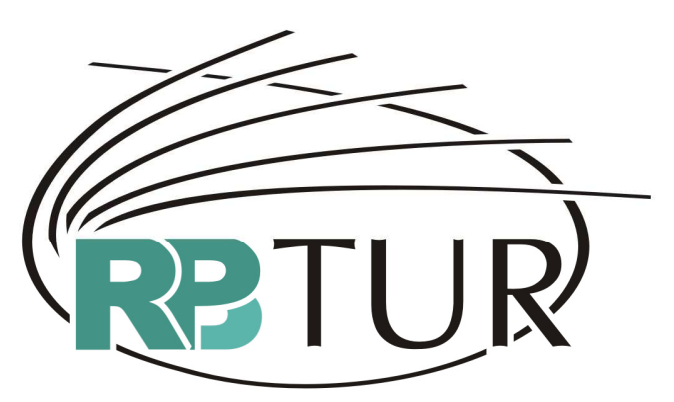

REVISTA BRASILEIRA DE PESQUISA EM TURISMO

\title{
RELAÇÃO ENTRE ATIVIDADE TURÍSTICA, APROPRIAÇÃO DO TERRITÓRIO E PATRIMÔNIO: UMA CONTRIBUIÇÃO PARA O PLANEJAMENTO SUSTENTÁVEL DO TURISMO NA BAHIA
}

\author{
RELATIONSHIP AMONG TOURISM, OWNERSHIP OF LAND \\ AND HERITAGE: A CONTRIBUTION TO THE PLANNING OF \\ SUSTAINABLE TOURISM IN BAHIA, BRAZIL
}

\section{RELACIÓN ENTRE TURISMO, PROPIEDAD DE LA TIERRA Y PATRIMONIO: UNA CONTRIBUCIÓN AL PLANEAMIENTO DE TURISMO SOSTENIDO EN BAHIA, BRASIL}

Natanael Reis Bomfim ${ }^{1}$

Djaneide Silva Argôlo

\begin{abstract}
RESUMO: O presente artigo busca, através de uma reflexão teórica, analisar a relação entre a apropriação do território pela atividade turística e seus impactos na cultura e no ambiente, chamando à atenção para a necessidade do planejamento sustentável na Costa do Cacau-Bahia. Para tal, recorremos à análise do discurso de diversos autores que tratam de forma interdisciplinar, a temática do Planejamento do turismo sustentável e sua relação com o desenvolvimento regional. Assim, tal proposta evidencia a necessidade de valorizar comunidades colocadas à margem do sistema econômico, que, muitas vezes, como forma de sobrevivência, aderem ao tráfico de drogas e mesmo à prostituição, ganhando essa última a dimensão do turismo sexual, que coloca o Brasil em escala mundial nesta atividade.
\end{abstract}

Palavras-chave: Turismo. Território. Planejamento Sustentável.

Abstract: This article aims to analyze the relationship among land appropriation by tourism and its impacts in culture and environment, claiming for sustainable tourism planning in Cacau Seashore in Bahia. Discourses of several authors of planning issues who write on sustainable tourism and regional development in an inter-disciplinary base were analyzed. To value those communities held in the periphery of the economic system, who many times get into drug dealing or prostitution (and sex tourism in which Brazil is a world leader) for survival is evidenced.

Keywords: Tourism. Territory. Sustainable Planning.

1 Doutor em Didática em Geografia pela Universidade do Quebec em Montreal. Professor Adjunto da Universidade Estadual de Santa Cruz, Ilhéus-Bahia, no Programa de Mestrado de Cultura e Turismo e no Curso de Licenciatura em Geografia. E-mail: natanaelreis@uol.com.br

2 Mestranda em Cultura e Turismo pela Universidade Estadual de Santa Cruz. Professora da Universidade Estadual de Santa Cruz, Ilhéus-Bahia, no Curso de História. E-mail: djaneideargolo@hotmail.com. 
ARGÔLO, Djaneide Silva; BOMFIM, Natanael Reis. Relação entre atividade turística, apropriação do território e patrimônio: uma contribuição para o planejamento sustentável do turismo na Bahia. Revista Brasileira de

ISSN: $1982-6125$ Pesquisa em Turismo. v. 2, n. 3, p. 41-53, nov. 2008.

Resumen: Este artículo pretende analizar la relación entre la apropiación de la tierra por concepto de turismo y los impactos que esto ocasiona en la cultura y el medio ambiente, y muestra la urgencia de un planeamiento de turismo sostenido en la Costa del Cacao- Bahía. Se analizaron los discursos de varios autores de planificación que escriben sobre turismo sostenido y desarrollo regional de forma interdisciplinar. Queda evidenta la necesidad de valorar estas comunidades que están en la periferia del sistema económico y que muchas veces parten, para sobrevivir, para el tráfico de drogas o la prostitución, inclusive para el turismo sexual que es uno de los destaques de Brasil.

Palabras clave: Turismo. Territorio. Planificación Sostenible.

\section{Introdução}

Em uma economia globalizada, a tendência é dar ênfase às produções de cultura que ocupem uma dimensão que vai além das fronteiras territoriais. Entretanto, comunidades locais respondem com representações simbólicas peculiares como alternativas à uniformidade apregoada pelo neoliberalismo. Assim, o patrimônio surge como uma construção da modernidade, um artifício criado no sentido do fortalecimento de uma pertença a um mesmo espaço simbólico, atribuindo uma transcendência a determinados símbolos culturais que atestam o caráter singular de uma determinada comunidade (BOMFIM, 2006).

Neste cenário, os debates e pesquisas sobre as questões relacionadas às identidades individuais e coletivas, às classes, ao gênero, à etnia, às diversas representações simbólicas e à preservação, recuperação e difusão dos acervos do patrimônio cultural material e imaterial estão ao seio das academias e fazem parte das preocupações da sociedade brasileira como um fermento ao Planejamento e Políticas Públicas. Por sua vez, o turismo como uma atividade produtiva mundial que interfere na organização desigual dos territórios, absorvidos pelos modos de produção e culturas, requer um controle do governo e da própria sociedade, exigindo, por um lado, a aplicação de políticas públicas e privadas e, por outro lado, uma melhor compreensão de conceitos interdisciplinares, uma vez que as ações engendradas em função da 
ARGÔLO, Djaneide Silva; BOMFIM, Natanael Reis. Relação entre atividade turística, apropriação do território e patrimônio: uma contribuição para o planejamento sustentável do turismo na Bahia. Revista Brasileira de

exploração da atividade turística trazem seus resultados socializados (CORIOLANO, 2005; DENCKER, 2004; BOMFIM, 2000; YÁZIGI, 1998).

Em nível regional, particularmente, na Bahia, as pesquisas interdisciplinares em Cultura e Turismo têm buscado compreender, de forma comparativa, a dimensão nacional e regional das etnias, das identidades e cultura (SILVA, 2005); identificar a figura da mulher baiana presente nas obras "amadianas" visando uma desautomatização de um esquema conceitual, posto sobre o Brasil, baseado em estereótipos presos, ainda ao desfrutável e exótico (SACRAMENTO, 2006) e investigar as representações simbólicas construídas pelos sujeitos a fim de compreender a evolução dos modos destas representações, segundo as dimensões correlatas do significante ${ }^{3}$ espacial e do significado ${ }^{4}$ sócio-cultural (BOMFIM, 2008).

Nessa perspectiva, a conjugação desses atores permite sustentar que há, pelo menos teoricamente, uma tendência à descentralização econômica, impondo novos papéis às regiões e cidades, "espaços fragmentados" pelas políticas públicas que delinearam planos Nacionais e Setoriais centrados nas realidades do território (SANTOS, 1997). Essas regionalizações, decorrentes da dinâmica de produção, são produzidas em processos de inclusão/exclusão, continuidade/descontinuidade, dando origem a economias desiguais e combinadas, produzindo desenvolvimento e subdesenvolvimento, como movimentos mutuamente determinantes do movimento desigual e conjunto do capital (SOJA, 1993).

Esses efeitos da globalização, das inovações técnicas e da terceira revolução industrial, propiciam uma sociedade de economia flexível cujos sócios passam a possuir maior disponibilidade às condições básicas de lazer, oferecendo esta estrutura, condição de emergência do turismo como atividade de grande significação principalmente nos países em desenvolvimento. Assim, o turismo absorve um caráter cultural, mas por formar um par perfeito com o

\footnotetext{
${ }^{3}$ Identificação dos elementos naturais e antrópicos, dos fatos, dos fenômenos, etc., através do desenho.

${ }^{4}$ Conceito ou sentido dado ao espaço.
} 

turística, apropriação do território e patrimônio: uma contribuição para o planejamento sustentável do turismo na Bahia. Revista Brasileira de

capitalismo, passa a ter função puramente comercial, e na era da globalização a prática da atividade turística tende a direcionar-se para pequenos lugares ou comunidades, uma vez que as localidades são os termos do destino, remetendo à teoria de globalização/fragmentação, pois à medida que globaliza, a atividade turística abre espaço ao local, por que o lugar com sua singularidade é o espaço onde o global se realiza, cada lugar é à sua maneira o mundo (SANTOS, 1994).

\section{A utopia do Turismo Sustentável}

Discutir sobre a atividade turística e desenvolvimento, implica em refletir sobre os termos sustentabilidade e planejamento. O primeiro, segundo Oliveira (2003), tem sido usado para expressar a relação entre as ações antrópicas e a capacidade da natureza em suportá-las, sem prejuízo para a mesma. Isto implica na elaboração do segundo, o planejamento, que deve nortear a não exceder a capacidade do ambiente, para não esgotá-lo ou destruí-lo. Assim posto, em dois movimentos a atividade turística pode contribuir com o desenvolvimento regional/local. Por um lado, respeitando a sustentabilidade da sociedade, da natureza e das culturas e, por outro lado, através da materialização capitalista no espaço, percebe-se apropriação de um território político e ideológico (BOMFIM, 2006). Aí o turismo pressupõe uma ruptura espaço-temporal não apenas com o mundo do trabalho, mas com os lugares e as culturas. Nessa dialética, vale ressaltar que em um determinado momento é aventada a hipótese de um turismo sustentável, contribuindo com o desenvolvimento regional/local, respeitando a natureza e preservando as culturas, e em outro, os resultados do processo de exploração da atividade turística têm fornecido dados que permitem afirmar a ocorrência acentuadas 
ARGÔLO, Djaneide Silva; BOMFIM, Natanael Reis. Relação entre atividade turística, apropriação do território e patrimônio: uma contribuição para o planejamento sustentável do turismo na Bahia. Revista Brasileira de

desigualdades sociais e degradação ambiental (CORIOLANO, 2005; YÁZIGI, 2003, 2002; BECKER, 2002; CARLOS, 2002; CHADEFAUD, 1987)

Para Becker (2002), há um momento de valorização seletiva de territórios, há a inserção da atividade turística na natureza sem deformá-la ou depredá-la excessivamente, referindo-se ao ecoturismo, o que complementa Coriolano (2005) ao sinalizar turismo rural, turismo da natureza, turismo em áreas indígenas, turismo em favelas ou em áreas sertanejas, acentuando que desse modo pequenos lugares ou empreendimentos encontram uma forma para integrar a cadeia produtiva do turismo, quando os territórios são valorizados pela sua acessibilidade e natureza, especialmente nas zonas costeiras de países tropicais ou mediterrâneos, por serem produtos de venda fácil, mercadorias valorizadas para populações de países temperados ou frios, podendo a atividade do turismo criar uma multiplicação de serviços, de empregos diretos e indiretos e de circulação de dinheiro, embora traga também efeitos perversos, principalmente no âmbito social, a exemplo da prostituição ligada à atividade turística.

$\mathrm{Na}$ Bahia, em particular na Costa do Cacau, alguns estudos têm apontado impactos mais acentuados, seja para as comunidades locais, como no ambiente. Por exemplo, Argôlo (2008) afirma que pescadores de mariscos e peixes, cabaneiros e feirantes do entorno da Baía de Camamu, mudaram suas atividades como formas de resistir ao processo de exclusão trazido pela atividade turística. Para sobreviver os pescadores foram transformados em barqueiros para o exercício da atividade turística, outros deixaram de pescar e se transformaram em donos de pequenos sítios, sobrevivendo de exploração de culturas de curta duração (feijão, milho, urucum) no aguardo das espécies nativas e suas épocas ou culturas que requeiram maior tempo para produzir, a exemplo de cravo da índia, dendê, guaraná, seringa, piaçava, pimenta do reino, etc. Outros começaram a produzir alguns tipos de artesanato, com fibras e cipós para o fabrico de cestos, fruteiras, peças de ornamento. Além dos que se estabeleceram como donos de pequenas vendas e outros. Já o estudo de Bomfim (2007), no município de Itacaré, revela comunidades isoladas às 
ARGÔLO, Djaneide Silva; BOMFIM, Natanael Reis. Relação entre atividade turística, apropriação do território e patrimônio: uma contribuição para o planejamento sustentável do turismo na Bahia. Revista Brasileira de

margens do Rio de Contas, que são excluídas do processo turístico local ou resistem, tentando preservar suas tradições culturais.

Constata-se, aqui, que a exploração do turismo, como atividade lucrativa e organizada com maior aporte de recursos, ocorre em parte pela decadência da atividade cacaueira, que se encontrava na condição de maior suporte econômico do estado da Bahia e também pelo crescente interesse da exploração da atividade turística em áreas do litoral brasileiro, que se constitui espaço muito privilegiado em relação às belezas naturais, e, extremamente adequado à prática desta atividade. Por outro lado, a inserção dessa atividade tem sido objeto de programas e projetos, objetivando a conservação ambiental dotando a natureza não só da condição de produto ou mercadoria para o planejamento sustentável do turismo, pressupondo-se, como afirma Oliveira (2003) que os recursos naturais, assim como os construídos pelo homem, têm um limite para absorver visitantes.

\section{Patrimônio, Atividade turística e Planejamento}

$\mathrm{Na}$ articulação, entre a realidade da prática social do turismo, a produção do conhecimento sobre esta prática e o seu planejamento, faz-se necessária uma breve abordagem do conceito de patrimônio. Inserido entre vários debates, o II Seminário Nacional de Gestão do Patrimônio Cultural (2004), realizado em Goiânia e organizado pela comissão de professores, como Márcia Bezerra, Manuel Fereira Lima Filho, Roque de Barros Laraia e Eliane Lopes e Heliane Prudente Luçany Bueno. Este aponta para a importância de conhecer e de preservar o patrimônio cultural de uma localidade a partir de estudos interdisciplinares (MARRA; BARRETOS, 2004), afinados com as definições da Constituição Federal de 1998 e de Barreto (1996).

Esses afirmam que Patrimônio Cultural não deve ser constituído apenas por edificações arquitetônicas e seus elementos, mas também como o conjunto de todos os utensílios, hábitos, usos e costumes, crenças e formas da vida 
ARGÔLO, Djaneide Silva; BOMFIM, Natanael Reis. Relação entre atividade turística, apropriação do território e patrimônio: uma contribuição para o planejamento sustentável do turismo na Bahia. Revista Brasileira de

cotidiana que fazem referência à identidade, à ação, à memória dos diferentes grupos que formam a sociedade brasileira. Nesta perspectiva, o conceito de patrimônio traz uma carga afetiva e simbólica. Assim, ele é também uma questão de paternidade, de herança, de transmissão de signos e significados, através do tempo, destes que deveriam constituir um valor e um laço sócionatural, à imagem de um laço de família, um vestuário, uma comida, um prédio, ou mesmo com uma árvore de um determinado lugar.

O patrimônio é, portanto, uma construção social (PRATS, 1997), um processo simbólico de legitimação social e cultural, baseado na seleção e ativação de determinados referentes que permitem representar uma determinada identidade.

Falar de patrimônio pressupõe, por isso, falar de identidades, na medida em que pode ser definido como uma síntese simbólica de valores identitários (SANTANA, 1998), que contribuem para um sentimento de pertença e de identificação de um coletivo social. Com efeito, esta capacidade de representação simbólica das identidades constitui um elemento central na atual definição do conceito de patrimônio. Enfim, este conceito não se resume apenas à cultura, traduzido como patrimônio cultural, inscrito na memória dos indivíduos, transmitido e regenerado pelas formas oral e escrita e identificado socialmente. Ele retoma a idéia de solidariedade entre as gerações e, com um olhar abrangendo o nosso passado, ultrapassa os limites da objetividade humana e faz intervir no tempo, na história, na paisagem, no lugar, no espaço.

Percebemos, então, que, através das concepções teóricas sobre patrimônio e atividade turística, existe um esforço de vários autores em estabelecer uma relação com a cultura e a identidade de um grupo social. Entretanto, o discurso é desprovido do contexto sócio-espacial que talvez nos permitisse melhor compreender a relação entre as práticas sociais na atividade turística e o planejamento dessa atividade.

Logo, faz-se necessário apreender as representações sociais, simbólicas e culturais, construídas pelos sujeitos, a fim de interpretar e compreender os diversos lugares turísticos; regular as relações entre grupos sociais e a 
ARGÔLO, Djaneide Silva; BOMFIM, Natanael Reis. Relação entre atividade turística, apropriação do território e patrimônio: uma contribuição para o planejamento sustentável do turismo na Bahia. Revista Brasileira de

atividade turística, bem como julgar e avaliar as práticas sociais através de atitudes e valores atribuídos ao seu espaço vivido.

Nesta perspectiva, os debates e pesquisas fazem relação ao patrimônio como uma tradução das diversas representações simbólicas, sua preservação, recuperação e difusão, servindo como fermento ao Planejamento do Turismo. Segundo Petrocchi (2001), o planejamento turístico identifica os segmentos específicos que poderão ser trabalhados com a oferta de produtos específicos que atendam às necessidades e desejos da demanda localizada, mas, para tanto, há a necessidade do envolvimento da população residente nesse processo, pois, o principal vendedor deste produto é quem mais o consome, neste caso, o seu residente.

O Turismo depende da população, em todos os aspectos, tanto em relação à imprescindível hospitalidade quanto aos investimentos necessários. Logo, o planejamento do turismo deve passar por um programa de conscientização da população relativamente à importância dessa atividade: os empresários devem se engajar nas questões políticas do seu município e os estudantes devem ser esclarecidos sobre o Turismo e o mercado de trabalho. Uma mudança cultural é necessária, a população deve enxergar e exigir providências concretas e corretas em prol do turismo.

Assim, todo o planejamento é uma ferramenta de poder significativo. Quando se escolhe uma das alternativas de diversos cenários futuros, a decisão é sobre aquela que mais interessa e beneficia o planejador, ou o grupo social ao qual pertence. Pode-se dizer que poder e planejamento são conceitos indissociáveis, pois toda elaboração de um plano envolve o sucessivo método de tomada de decisões que comprometerão em maior ou menor grau um grupo de pessoas.

A atividade turística realizada sem planejamento tem grandes possibilidades de produzir mais impactos negativos do que positivos. 0 fundamental é a intenção de planejar, buscando a sustentabilidade em modelos de gestões de políticas públicas coordenadas e integradas, aumentando a capacidade socioeconômica, ambiental e cultural da atividade. 0 
ARGÔLO, Djaneide Silva; BOMFIM, Natanael Reis. Relação entre atividade turística, apropriação do território e patrimônio: uma contribuição para o planejamento sustentável do turismo na Bahia. Revista Brasileira de

planejamento da atividade turística envolve a escolha de um cenário futuro que atenda aos interesses da maioria da população de um município, estabelecendo limites e regras e impondo condições que contribuem para o seu sucesso.

É na elaboração do planejamento que o Poder do Estado se manifesta com maior clareza, pois se trata de modificar uma tendência por outra previamente escolhida.

Sobre o Planejamento e Políticas Públicas, destacamos, aqui, o Plano Nacional de Turismo (PNT), articulado com o Ministério do Turismo que, através de suas diretrizes, metas e programas do setor, visam desenvolver 0 produto turístico brasileiro com qualidade, contemplando as diversidades regionais, culturais e naturais; além de estimular e facilitar o consumo desse produto nos mercados nacional e internacional.

Salientamos, ainda, o Programa de Regionalização do Turismo (PRT) que visa, em parceria com o SENAC, SESC e SEBRAE, estruturar atrativos e infraestrutura a fim de oferecer produtos turísticos diferenciados, bem como implantar vários roteiros turísticos em diferentes estados. Neste sentido, as orientações básicas dadas pelo Ministério do Turismo (2006) ao Turismo Cultural apontam para o desenvolvimento e a oferta de produtos do Turismo Cultural agregados à promoção da diversidade cultural brasileira, da participação e do bem-estar das comunidades.

Mas, por um lado, para alcançar resultados significativos, entendemos a necessidade de esforços da comunidade local, o poder público e os institutos de pesquisa, adotando ações estratégicas, tais como: capacitação de recursos humanos, abertura de linhas de financiamento de projetos ligados ao turismo, ampliação de infra-estrutura turística, estabelecimento de programas de cooperação empresarial, revitalização de áreas de patrimônio histórico-cultural, entre outras.

Por outro lado, faz-se necessário uma reflexão sobre conceitos, teorias e métodos de investigação em turismo, entendendo que a pesquisa é um elemento estratégico indispensável para a liderança dos mercados e a 
ARGÔLO, Djaneide Silva; BOMFIM, Natanael Reis. Relação entre atividade turística, apropriação do território e patrimônio: uma contribuição para o planejamento sustentável do turismo na Bahia. Revista Brasileira de

ISSN: $1982-6125$ Pesquisa em Turismo. v. 2, n. 3, p. 41-53, nov. 2008.

determinação de futuros alternativos dentro da vocação específica de cada região. Isso implica analisar os lugares e suas impregnações e, por vezes, suas diversas realidades e identidades. Assim, patrimônio, turismo e planejamento, são realidades que convergem no cotidiano de vários atores responsáveis pela elaboração e veiculação de discursos relacionados com uma pretensa necessidade de preservação dos bens naturais e culturais.

\section{Considerações Finais}

Antes das considerações finais, salientamos que geograficamente, o espaço baiano está dividido em sete messorregiões como Extremo Oeste Baiano, Vale do São Francisco, Centro Norte Baiano, Nordeste Baiano, Metropolitana de Salvador, Centro Sul Baiano e Sul Baiano. Este conceito de região, oficialmente criado pelo IBGE (1988), é utilizado para fins de recenseamento e de planejamento territorial.

Neste cenário, uma aplicação de conhecimentos teóricos que abordem o Patrimônio cultural numa perspectiva de identidade cultural e sua relação com a atratividade turística se justifica, na medida em que os significados atribuídos aos bens materiais e imateriais, pelos atores sociais das comunidades locais, nos permitam conhecer o conteúdo dos produtos turísticos em três dimensões, a saber: a científica, que busca defini-lo como um patrimônio que ultrapassa aquela visão cristalizada do passado ou do estético; o sócio-cultural, na medida em que os produtos possam servir como um atrativo turístico que revele a identidade das comunidades e estreite os laços entre os povos. E, finalmente, o econômico, cuja identidade dos produtos possa maximizar ganhos para as comunidades locais, contribuindo, assim, para um desenvolvimento regional na abrangência do Turismo Cultural.

Entendemos aqui que, em longo prazo, será possível efetivar uma atividade turística sustentável, associado à necessidade de desenvolvimento 
ARGÔLO, Djaneide Silva; BOMFIM, Natanael Reis. Relação entre atividade turística, apropriação do território e patrimônio: uma contribuição para o planejamento sustentável do turismo na Bahia. Revista Brasileira de

sustentável para as comunidades locais, através do Turismo Cultural, a partir da economia globalizada, amparada no terceiro setor, através de: publicidade, comunicação, pesquisa, empresas de comércio, finanças, saúde, educação, lazer entre outros.

Para tal intento ser alcançado, alguns objetivos são sugeridos: levantar junto aos órgãos competentes, os municípios envolvidos no Programa de Certificação em Turismo Sustentável (PCTS), Empreendedorismo Rural e Programa Setorial de Artesanato; identificar os produtos turísticos preservados e valorizados pela comunidade local, tendo como base o grau de preservação e valorização que os atores sociais Ihes atribuem; classificar e formatar os produtos turísticos nas dimensões de patrimônio (forma arquitetura, monumento, trabalhos de arte, atividades, alimentos, língua, modo de vida, paisagem), respeitando as características identitárias dos sujeitos e das localidades; classificar as informações recolhidas a partir das percepções dos sujeitos e (re) construir (ampliar) o conceito de patrimônio nas suas diversas dimensões; integrar essas comunidades ao PCTS; estabelecer parceria com instituições públicas e privadas, para desenvolver ações de sensibilização, de comunicação e de divulgação dos produtos turísticos.

Nesta perspectiva, ambientes de geração de empregos podem ser criados, reduzindo as desigualdades regionais e promovendo a inclusão social, com a utilização sustentável do patrimônio material e imaterial dos municípios identificados e mapeados, oportunizando, assim, empreendimentos geradores de emprego e renda.

\section{Referência Bibliográfica}

ARGÔLO, D. S. Avaliação da influência da atividade turística no processo de (re)significação pela comunidade da baía de Camamu-Bahia. Pesquisa em andamento no Programa de Mestrado em Cultura e Turismo. Bahia, Universidade Estadual de Santa Cruz, 2008. 
ARGÔLO, Djaneide Silva; BOMFIM, Natanael Reis. Relação entre atividade turística, apropriação do território e patrimônio: uma contribuição para o planejamento sustentável do turismo na Bahia. Revista Brasileira de

BECKER, B. Políticas e planejamentos do turismo. In: YÁZIGI, Eduardo. Turismo: Espaço, paisagem e cultura. São Paulo, Hucitec, 2002.

BOMFIM, N. R. Uma perspectiva educacional da relação entre cultura e ambiente. Encontro de Geografia da UNICSUL - Território, Sociedade e Meio Ambiente. São Paulo, 2006.

BOMFIM, N. R. A noção social do território. Bahia, Edtus, 2008 (prelo).

BOMFIM, N. R. Identidade e atratividade do patrimônio cultural: uma contribuição para formatação de produtos turísticos preservados e valorizados pela comunidade local da costa do cacau. Pesquisa em desenvolvimento, financiado pelo CNPQ, 2007-2009.

BOMfIM, N. R. Patrimônio, turismo e planejamento: formatação de produtos. Bahia, Mimeografado, 2008.

CARLOS, A. F. A. O Turismo e a produção do não lugar. In: YÁZIGI, Eduardo. Turismo: Espaço, paisagem e cultura. São Paulo, Hucitec, 2002.

CHADEFAUD, M. Methode d'analise d'un floux touristique au niveau local el regional. Lês Cahiers du Tourisme. Paris, Serie C, n. 17, 1987.

CORIOLANO L. N. Turismo e Geografia - abordagens críticas. Fortaleza, Ed. UECE, 2005.

DENCKER, A. F. M. Métodos e técnicas da pesquisa em Turismo. São Paulo, Futura, 2004.

DIAS, R. Turismo sustentável e meio ambiente. São Paulo, Atlas, 2003.

DIAS, R. Planejamento do Turismo. São Paulo, Atlas, 2003.

MINISTÉRIO DO TURISMO - Secretaria Nacional de Políticas de Turismo. Turismo Cultural: orientações básicas. Brasil, 2006.

OLIVEIRA, F. V. Capacidade de carga nas cidades históricas. Campinas, Papirus, 2003.

PETROCCHI, M. Turismo: planejamento e gestão. São Paulo, Futura, 2001.

SACRAMENTO, S. M. P. A nação e o feminino em Jorge Amado. Légua \& Meia. v. 4, p. $168-175,2006$.

SANTOS, M. O mundo, o Brasil e a globalização: o horror não dura eternamente. In: Rumos do desenvolvimento. Rio de Janeiro, 1997. 
ARGÔLO, Djaneide Silva; BOMFIM, Natanael Reis. Relação entre atividade turística, apropriação do território e patrimônio: uma contribuição para o planejamento sustentável do turismo na Bahia. Revista Brasileira de

ISSN: $1982-6125$ Pesquisa em Turismo. v. 2, n. 3, p. 41-53, nov. 2008.

SANTOS, M. Técnica, espaço e tempo. São Paulo, Hucitec, 1994.

SOJA, E. W. Geografias pós modernas: a reafirmação do espaço na teoria sócio-crítica. Rio de Janeiro, Zahar, 1993.

YÁZIGI, E. Turismo uma esperança condicional. 3a. ed., Rio de Janeiro, Global Universitária, 2003.

YÁZIGI, E. Turismo: espaço, paisagem e cultura. São Paulo, Hucitec, 2002.

\section{Bibliografia}

BOMFIM, N. R. O conceito de patrimônio numa perspectiva multidisciplinar: contribuições para uma mudança de enfoque. Revista Turismo \& Desenvolvimento. São Paulo, vol. 5, n.1, p. 27-35, 2005.

SILVA, A. C. Geografia e lugar social. São Paulo, Contexto, 1991. 